\title{
Lignin Synthesis Related Genes with Potential Significance in the Response of Upland Cotton to Fusarium Wilt Identified by Transcriptome Profiling
}

\author{
Jianan Hou ${ }^{1,2} \cdot \mathrm{Fu}^{\prime}$ an Zhao ${ }^{2} \cdot$ Xiaojie Yang ${ }^{2} \cdot \mathrm{Wu} \mathrm{Li}^{2} \cdot$ Deyi Xie $^{2} \cdot$ Zhongjie Tang $^{2} \cdot$ Shuping $\mathrm{Lv}^{2} \cdot$ Lihong Nie $^{2}$. \\ Yao Sun ${ }^{2} \cdot$ Mengmeng Wang ${ }^{2} \cdot$ Yajing Zhu ${ }^{2} \cdot$ Xiaopei $\mathrm{Bo}^{2} \cdot$ Qianwen Zhang ${ }^{3} \cdot$ Yuanming Zhao $^{2} \cdot$ Weiping Fang ${ }^{1,3,4}$ (D)
}

Received: 11 August 2020 / Accepted: 22 November 2020 / Published online: 12 January 2021

(C) The Author(s) 2021

\begin{abstract}
Fusarium wilt, caused by the fungus Fusarium oxysporum Schlecht.f. sp. vasinfectum (Fov) is a destructive soil-borne cotton disease. To profile the genes and pathways responding to Fov infection, we compared transcriptomic responses before and after F. oxysporum inoculation in a highly resistant cotton cultivar, Yumian21, and a highly susceptible cultivar, Jimian11. Although the overall gene expression pattern was downregulated in both cultivars, the global gene expression in the resistant cultivar was stronger than that in the susceptible cultivar. In addition, the expressed genes of two cultivars mostly differed in "cellular process," "single-organism process," "metabolic process," and "response to stimulus" functional groups in the biological process Gene Ontology category: the upregulated differentially expressed genes (DEG) were largely enriched in the resistant cultivar, while the downregulated DEGs were largely enriched in the susceptible cultivar. Phenylpropanoid biosynthesis and phenylalanine metabolism are the key metabolic pathways in cotton in response to Fov. We found that lignin plays a potential role in cotton resistance to Fov. Two coding genes, caffeic acid 3-O-methyltransferase and peroxidase2, as well as the two transcription factors MYB46 and MYB86, are possibly involved in the accumulation and synthesis of lignin. Furthermore, the result showed that the quantification of lignin could be potentially used as a selection tool to identify Fusarium wilt resistant cotton.
\end{abstract}

Keywords Lignin $\cdot$ Fusarium oxysporum $\cdot$ Transcriptome $\cdot$ Upland cotton

\author{
Abbreviations \\ COG Cluster of Orthologous Groups \\ DEG Differentially Expressed Gene \\ EggNOG Evolutionary Genealogy \\ of Genes: Non-supervised Orthologous Groups \\ ELISA \\ Enzyme-Linked Immunosorbent Assay \\ FC Fold Change \\ Communicated by: Zhi-Liang Zheng \\ Weiping Fang \\ hncot@163.com \\ 1 School of Life sciences, Henan University, Kaifeng 475004, Henan, \\ China \\ 2 Economic Crop Research Institute, Henan Academy of Agricultural \\ Sciences, Zhengzhou 450002, Henan, China \\ 3 School of Agricultural Sciences, Zhengzhou University, \\ Zhengzhou 450001, Henan, China \\ 4 Henan Association for Science and Technology, \\ Zhengzhou 450008, Henan, China
}

$\begin{array}{ll}\text { FDR } & \text { False Discovery Rate } \\ \text { FPKM } & \text { Fragments Per Kilobase per Million } \\ \text { Fov } & \text { Fusarium oxysporum } \\ & \begin{array}{l}\text { Schlecht.f. sp. vasinfectum } \\ \text { FW }\end{array} \\ \text { Fusarium wilt } \\ \text { KO } & \text { Gene Ontology } \\ \text { KOG } & \text { Kyoto Encyclopedia of Genes and Genomes } \\ \text { Nr } & \text { Eukaryotic Orthologous Groups } \\ \text { PDA } & \text { Non-redundant } \\ \text { POD } & \text { Potato-Dextrose Agar } \\ \text { qRT-PCR } & \text { Peroxidase } \\ \text { TF } & \text { Trantitative real-time PCR }\end{array}$

\section{Introduction}

Cotton (Gossypium hirsutum L.) is an important industrial crop that provides natural fibers and oilseeds (Ullah et al. 2017). Cotton Fusarium wilt (FW), caused by the soil-borne fungus Fusarium oxysporum Schlecht. F. sp. Vasinfectum 
(Atk.) Snyd. \& Hans (Fov) (Assigbetse et al. 1994), is a major disease of cotton capable of causing significant economic loss worldwide (Cianchetta and Davis 2015). Fov infects the roots and rapidly colonizes the vascular system of susceptible cotton hosts, causing vascular discoloration, wilting, and the eventual death of the plant (Dowd et al. 2004). FW is difficult to prevent because of long-term persistence of chlamydospores in soil and Fov's resting structures in host xylem vessels (Mei et al. 2014). In China, the spread of FW is of great concern due to the limited knowledge about key aspects of disease epidemiology and the lack of effective management models, including resistant cultivars and soil management approaches.

Plants and their pathogens often evolve through competitive interactions and form complex relationships (Chisholm et al. 2006; Dangl and Jones 2001). The first line of plant defense system is a physical barrier composed of the waxy cuticle and cell wall. If the first line of defense is breached, the plant must resort to a different set of defense mechanisms, such as toxins and enzymes. Plants use their innate immune system to fight against pathogens (Malinovsky et al. 2014). With the primary immune system, plants recognize microbe-associated molecular patterns of potential pathogens through pattern recognition receptors that mediate a basal defense response. Plant pathogens suppress this basal defense response by means of effectors that enable them to cause disease. With the secondary immune system, plants have the ability to recognize effector-induced perturbations of host targets through resistance proteins that mediate a strong local defense response that stops pathogen growth (Jones and Dangl 2006). Currently, the possible resistance mechanisms of cotton's defense against FW are poorly understood.

In cotton plants, a series of metabolic changes can be induced during the initial response to pathogen invasion. For example, the affected cells produce secretions which can bury or encase pathogens; they may also block vessels by increasing metabolic activities, thereby limiting the spread of pathogens (Shi et al. 1991; Shi et al. 1992; Shi et al. 1993). Additionally, phenolic compounds such as gossypol and its derivatives may be induced from infected cells, further inhibiting the spread of $F$. oxysporum (Hall et al. 2011; Mellon et al. 2014; Zhang et al. 1993). Furthermore, many kinds of transcription factors, protein kinases, and phytohormones are involved during the response process of cotton plants to Fov: for example, the cotton MAPK kinase GhMPK20 negatively regulates resistance to $F$. oxysporum, and the expression of GhMKK6 contributes to the immune response in cotton (Wang et al. 2018; Wang et al. 2017). Notably, both salicylic acid and jasmonic acid can contribute to the over-expression of pathogenesis-related genes in cotton plants (Akhunov et al. 2008).
Lignin plays important roles in the growth and development of plants, defending against a variety of biotic and abiotic stresses. It acts as a physical and chemical barrier to limit pathogen colonization and restrict pathogen growth in a wide range of plant species (Bonello and Blodgett 2003; Hückelhoven 2007; Zhang et al. 2017). Lignin content has been used as a biochemical marker of an activated immune response in a multitude of species (Adams-Phillips et al. 2010; Kishi-Kaboshi et al. 2010): lignin content in disease-susceptible tomato varieties is significantly lower than that in disease-resistant cultivars (Mandal et al. 2013); the composition and accumulation of lignin strengthens the cell walls and enhances plant resistance to fungi in pepper plants (Novo et al. 2017); and lignin content increases in Chinese cabbage when it is infected by Erwinia carotovora (Zhang et al. 2007). The lignin biosynthesis genes play significant roles in resisting the invasion of pathogens through the salicylic acid defense pathway in Arabidopsis thaliana (Tronchet et al. 2010). When rice suffers pathogen invasion, the activity of cinnamoyl-CoA increases to positively regulate lignin synthesis (Kawasaki et al. 2006) and OsAAE3 negatively regulates lignin synthesis (Liu et al. 2017). In maize, genes HCT1806, HCT4918 and ZmCCOAOMT2 are involved in the resistance of various pathogens by participating in the biosynthesis of lignin (Wang et al. 2015; Yang et al. 2017). Lignin plays a critical role in cotton resistance to Verticillium dahliae: the resistant cotton varieties show a high level of lignin deposition and ligninlike phenolic polymers, (Smit and Dubery 1997) and the lignin content is positively correlated with resistance to V. dahliae (Xu et al. 2011). The GhDIR1, GbERF1-like, GhUMC1, GhWAT and GhLAC15 genes improve cotton resistance to $V$. dahliae via activating or strengthening lignin synthesis (Guo et al. 2016; Shi et al. 2012; Tang et al. 2019b; Zhang et al. 2019; Zhu et al. 2018). We hypothesize that lignin synthesis-related genes contributed to the cotton resistance to Fov through positively regulating lignin synthesis and enhancing the lignin content.

In the present study, one highly resistant cotton cultivar Yumian 21 and one highly susceptible cultivar Jimian 11 were chosen to analyze the molecular mechanism underlying cotton response to Fov. The gene expression patterns and functions of differentially expressed genes (DEGs) were analyzed based on the RNA-seq data. We found that the deposition and accumulation of lignin play a potential role during the response of cotton to Fov invasion. Two coding genes: caffeic acid 3-Omethyltransferase and peroxidase2, and two transcription factors: MYB46 and MYB86 are possibly involved in the accumulation and synthesis of lignin. Lignin quantification can be used as a selection tool to identify FW resistant cotton. The present study can also be served as a resource for future research addressing the resistance mechanism of cotton to Fov. 


\section{Results}

\section{Resistant Phenotype of Two Cotton Cultivar after Inoculation with Fov}

When resistant and susceptible cultivars were inoculated with $F$. oxysporum, the phenotype of disease began to appear in 16 days. The resistant cultivar survived well and only exhibited a slightly shorter plant size (Fig. 1A and C). On the contrary, the susceptible cultivar showed several symptoms including dwarfing, leaf wilting, defoliation, vascular discoloration and necrosis, and death of plants (Fig. 1B and D). The histochemical analysis of lignin in stem cross-sections showed no significant differences of lignin staining between the resistant cultivar inoculated with distilled water (Fig. S1 A), and the susceptible cultivar inoculated with distilled water or Fov (Fig. S1 B and D). However, the lignin staining of the resistant cultivar inoculated with Fov was significantly darker than the susceptible cultivar inoculated with Fov (Fig. S1 C and D).

\section{The Quality of Sequencing and Validation by qRT-PCR}

The 12 libraries were sequenced using the Illumina HiSeq $\mathrm{X}$ Ten sequencing platform. As shown in Table S1,115,754,914 to $160,378,098$ clean reads were obtained for the resistant cultivar, and $122,188,604$ to $159,256,750$ clean reads for the susceptible cultivar. A total of $102,783,932$ to $143,330,164$ mapped reads were obtained from the resistant cultivar and $113,234,260$ to $139,348,730$ mapped reads were obtained from the susceptible cultivar. The comparison efficiency range was between $83.92 \%$ and $93.30 \%$. The Q30 base percentage of each sample was between $92.46 \%$ and $95.18 \%$. The GC content was between $43.71 \%$ and $45.37 \%$ in the 12 libraries. A total of 76,467 expressed genes were identified and annotated by blasting the sequences against seven public databases. A total of 26,264 (34.3\%), 28,084 (36.7\%), 18,063 (23.6\%), 40,402 (52.8\%), 51,819 (67.8\%), 68,987 (90.2\%) and $43,424(56.8 \%)$ unigenes had significant hits (E value $\leq$ $10^{-5}$ ) in the COG, GO, KEGG, KOG, Swiss-Prot, EggNOG and $\mathrm{Nr}$ databases, respectively (Table S2).

We compared RNA-Seq data with real-time RT-PCR data for 18 randomly selected DEGs that showed up-regulation or down-regulation in response to Fov infection according to RNA-Seq (Excel S1). The results of the qRT-PCR data for these 18 genes were consistent with those obtained via RNAseq analysis, which indicated that the changes in expression detected by RNA-seq were accurate (Fig. S2).

\section{Patterns of Gene Upland Cotton in Response to Infection by Fov}

In our experiment, a false discovery rate $(\mathrm{FDR})<0.05$ and fold change $(\mathrm{FC})=1.5$ were used as the thresholds for assessing significant differences in gene expression. A total of 1055 DEGs were detected in the resistant cultivar, including 477 (45\%) upregulated genes and 578 (55\%) downregulated genes. A total of 995 DEGs were identified in the susceptible cultivar, including 369 (37\%) upregulated genes and
Fig. 1 Disease symptoms on the Yumian21 resistant cultivar and the Jimian11 susceptible cultivar inoculated with Fusarium oxysporum. (A) the Yumian21 inoculated with distilled water; (B) the Jimian11 inoculated with distilled water; (C) the Yumian21 inoculated with $F$. oxysporum;

(D) the Jimian11 inoculated with F. oxysporum
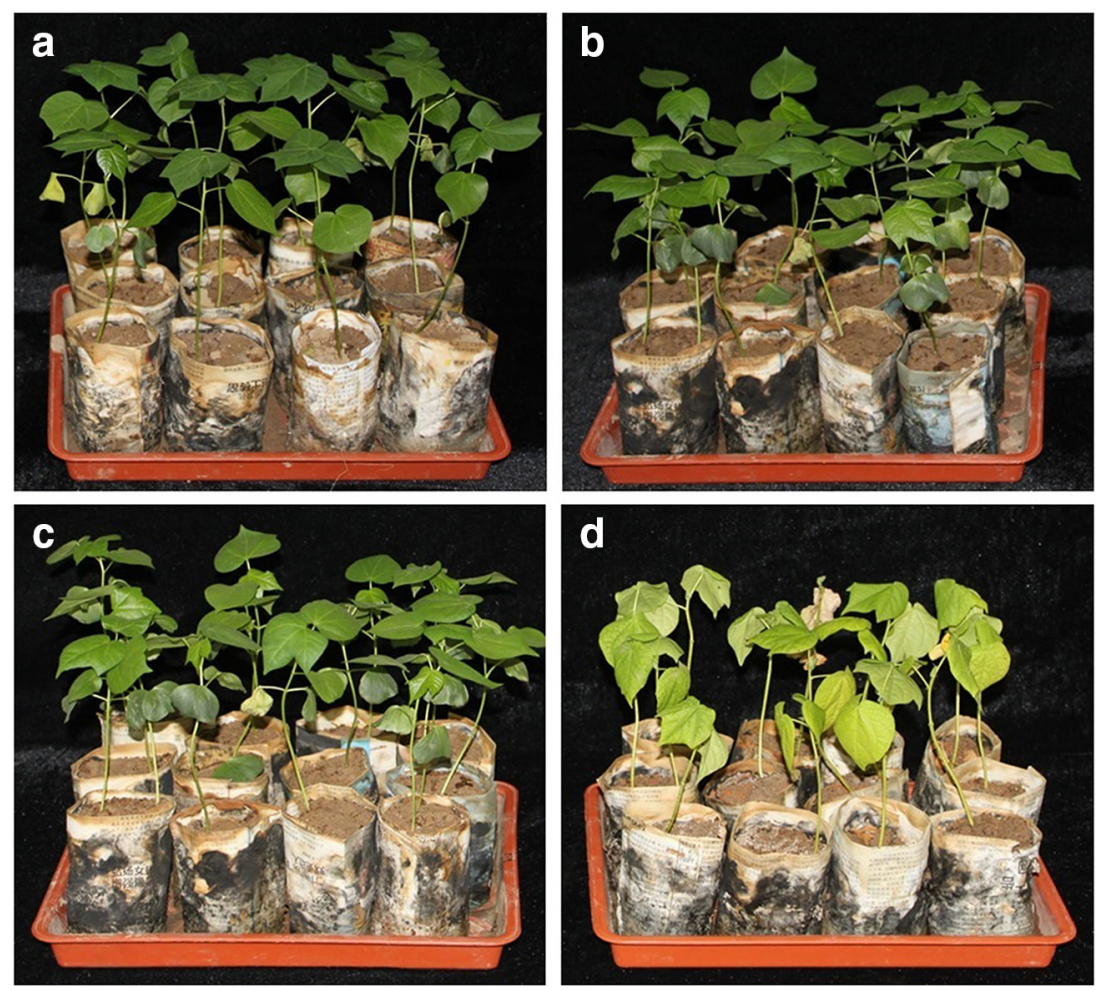
$626(63 \%)$ downregulated genes (Fig. 2A). Genes were mostly downregulated rather than upregulated when both cultivars were inoculated with Fov. In addition, the number of downregulated genes (578) in the resistant cultivar was less than that (626) in the susceptible cultivar. A total of 146 genes were either up-regulated or down-regulated in resistant and susceptible cultivar: 27 DEGs were upregulated in both cultivars; 103 DEGs were downregulated in both cultivars; ten DEGs were upregulated in the resistant cultivar but downregulated in the susceptible cultivar; and six DEGs were upregulated in the susceptible cultivar but downregulated in the resistant cultivar (Fig. 2B). The concrete DEGs of the resistant cultivar and the susceptible cultivar after treatment with Fov are listed in Excel S2 and S3, respectively.

\section{Functional Classification of DEGs}

A total of 1055 DEGs were divided into three main GO categories: biological process, cellular components, and molecular functions for the resistant cultivar. Most of the GO terms were assigned to biological process (56.13\%), followed by cellular component $(31.30 \%)$ and molecular functions (12.57\%). Of 995 DEGs in the susceptible cultivar, $54.82 \%, 32.36 \%$ and $12.82 \%$ were assigned to biological process, cellular component and molecular function GO terms, respectively (Excel S4 and S5). The greatest proportion of the GO categories consisted of biological process in both resistant and susceptible cultivars.

In the resistant cultivar, 2887 upregulated and 3237 downregulated DEGs were attributed to 19 groups of the biological process category. Among them, 349 (12.08\%) upregulated and $399(12.32 \%)$ downregulated genes were involved in "cellular process"; 343 (11.88\%) upregulated and 412 $(12.73 \%)$ downregulated genes were involved in "single-organism process".

In the susceptible cultivar, the upregulated DEGs were distributed into 18 groups of the biological process category. Of 1932 upregulated genes, 264 genes (13.66\%) were involved in "metabolic process," followed by 262 genes $(13.56 \%)$ involved in "cellular process." The downregulated DEGs were distributed into 16 groups of the biological process category. Of 3667 downregulated genes, 471 (12.84\%) were involved in "cellular process", followed by 469 genes $(12.78 \%)$ involved in "single-organism process".

In "biological process" GO categories, the number of upregulated genes in the resistant cultivar was significantly higher than that in the susceptible cultivar (Fig. 3). The upregulated DEGs were mostly enriched in four functional groups: the "cellular process" group (349 DEGs in resistant, 262 in susceptible), "single-organism process" group (343 in resistant, 257 in susceptible), "metabolic process" group (329 in resistant, 264 in susceptible), and "response to stimulus" group (307 in resistant, 223 in susceptible). In contrast, the number of downregulated genes in the susceptible cultivar was significantly higher than that in the resistant cultivar (Fig. 3). The downregulated DEGs were mostly enriched in "cellular process" (399 in resistant, 471 in susceptible), "single-organism process" (412 in resistant, 469 in susceptible), "metabolic process" (389 in resistant, 446 in susceptible), and "response to stimulus" (358 in resistant, 408 in susceptible). The resistant cultivar and the susceptible cultivar mostly differed in "cellular process," "single-organism process," "metabolic process," and "response to stimulus" functional groups: the upregulated DEGs were largely enriched in the resistant
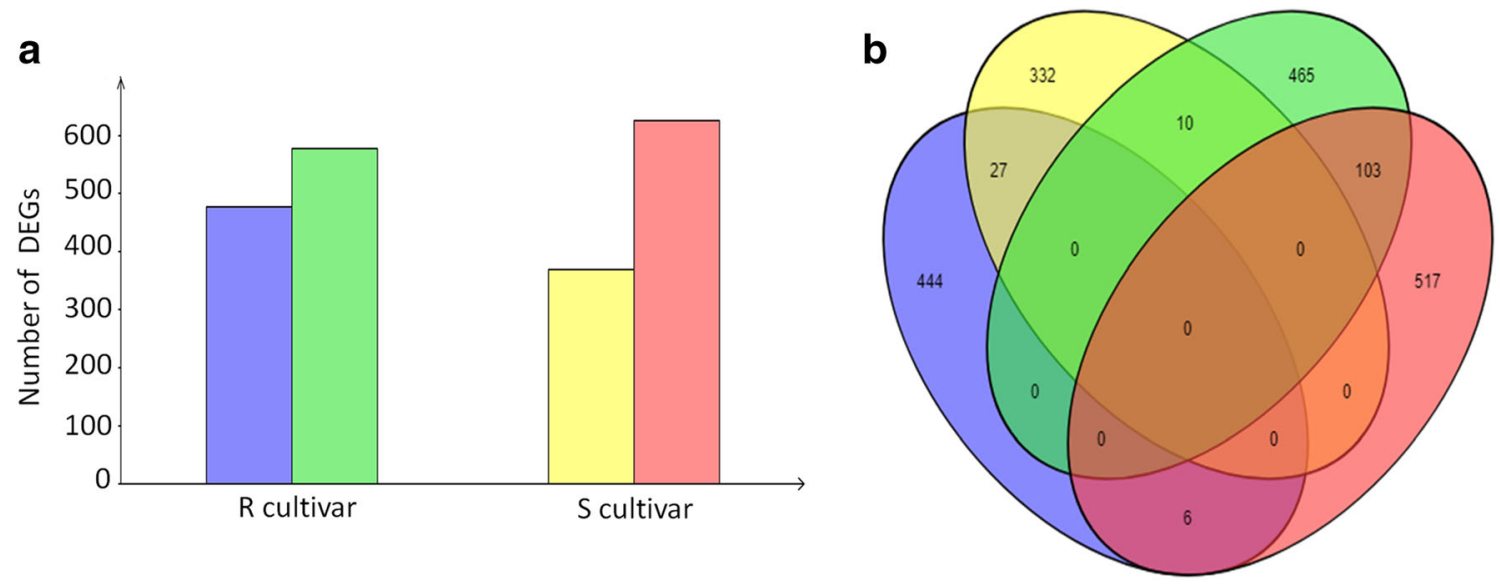

R(upregulation) $\quad \square R$ (downregulation)

S(upregulation)

$\mathrm{S}$ (downregulation)

Fig. 2 Differentially expressed gene (DEG) analysis of the Yumian21 resistant cultivar and the Jimian11 susceptible cultivar inoculated with Fusarium oxysporum. (A) total number of upregulated and

downregulated DEGs in the resistant and susceptible cultivars; (B) Venn diagrams of DEGs in the resistant and the susceptible cultivars 


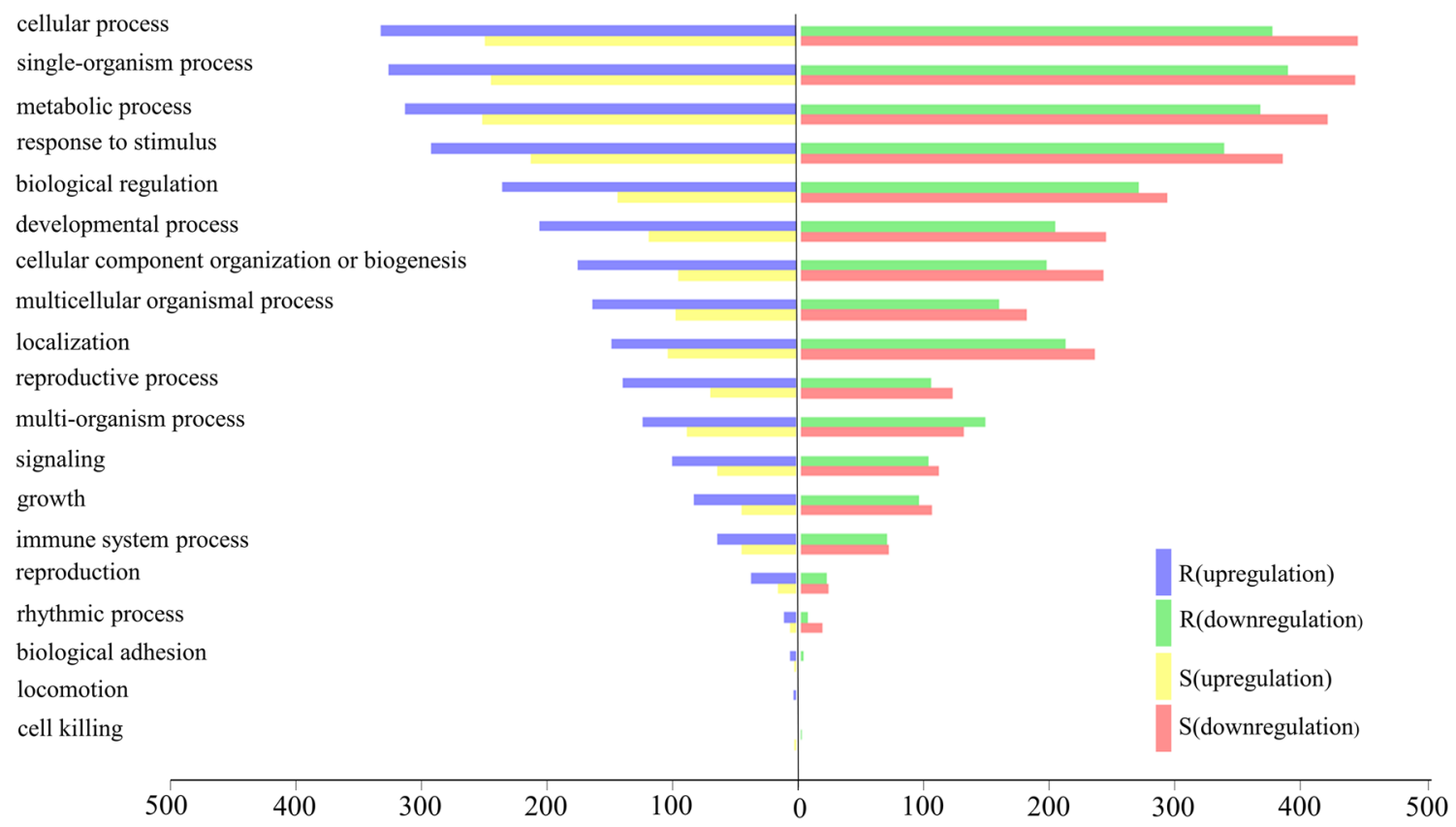

Fig. 3 Comparison of the biological process in GO classification of the resistant and the susceptible cultivars inoculated with Fusarium oxysporum. The $\mathrm{x}$-axis represents the number of DEGs and the $\mathrm{y}$-axis represents specific function groups

cultivar; the downregulated DEGs were largely enriched in the susceptible cultivar.

\section{KEGG Enrichment Analysis of Cotton Infection of Fov}

For the resistant cultivar, 207 DEGs (87 upregulated vs 120 downregulated) were identified in the 74 KEGG pathway by BLAST analysis against the KEGG database. The DEGs were significantly enriched in the first 20 pathways with the lowest $p$ value when the resistant cultivar was inoculated with Fov (Fig. 4, the specific data was listed in Excel S6). The top three highly enriched pathways with the largest enrichment factors, the largest number of DEGs, and the lowest $\mathrm{p}$ value were phenylpropanoid biosynthesis (ko00940), phenylalanine metabolism (ko00360), and pentose and glucuronate interconversions (ko00040) in the resistant cultivar. For the susceptible cultivar, 210 DEGs (88 upregulated vs 122 downregulated) were activated in the 84 KEGG pathway. The 20 with the most reliable pathway functional enrichment of the susceptible cultivar after inoculation with Fov is shown in Fig. S3 (Specific data in Excel S7). The top three highly enriched pathways were phenylpropanoid biosynthesis (ko00940), phenylalanine metabolism (ko00360), and flavonoid biosynthesis (ko00941); the phenylpropanoid biosynthesis (ko00940) and phenylalanine metabolism (ko00360) pathways were the most noteworthy KEGG pathways in both cultivars. These results showed phenylpropanoid biosynthesis and phenylalanine metabolism are the key metabolic pathways in cotton in response to Fov.

\section{Transcription Factors (TFs) Involved in Cotton Infection of Fov}

We investigated the distribution of transcription factors when two cultivars of cotton were infected with Fov. We found that the DEGs have transcription factors belong to AP2/ERF, MYB, NAC, bHLH, bZIP and WRKY families (Table 1). The numbers of upregulated TFs (30) exceeded downregulated TFs (15) in the resistant cultivar. However, the number of downregulated TFs (28) exceeded upregulated TFs (11) in the susceptible cultivar. We found most TFs belong to AP2/ERF and MYB (18 and 24, respectively). In the AP2/ERF family, twelve genes were upregulated, while one was downregulated in the resistant cultivar. However, only two genes were upregulated, while three were downregulated in the susceptible cultivar. In the MYB family, twelve genes were upregulated and four were downregulated in the resistant cultivar. Two genes were upregulated and twelve were downregulated in the susceptible cultivar. In the resistant cultivar, the total number of upregulated genes (24) of these two families was significantly higher than total downregulated genes (5). In the susceptible cultivar, the total number of upregulated genes (4) of these two families was significantly lower than total downregulated genes (15).

\section{Genes Related to Disease Resistance}

We found that two genes: caffeic acid 3-O-methyltransferase (evm.TU.Gh A09G1053) and Peroxidase 2 (evm.TU.Gh D09G1208) were likely involved in resistance 
Fig. 4 Pathway functional enrichment of DEGs in the Yumian21 resistant cultivar inoculated with Fusarium oxysporum. The $\mathrm{x}$-axis represents the enrichment factor (rich factor) which is the ratio of the foreground value (the number of DEGs) and the background value (total gene amount). The y-axis shows the pathway names. A larger value of the rich factor indicates a higher enrichment value. The color indicates the $p$ value, A lower $p$ value refers to a more significant enrichment. Point size indicates DEG number and larger dots refer to higher numbers of DEGs

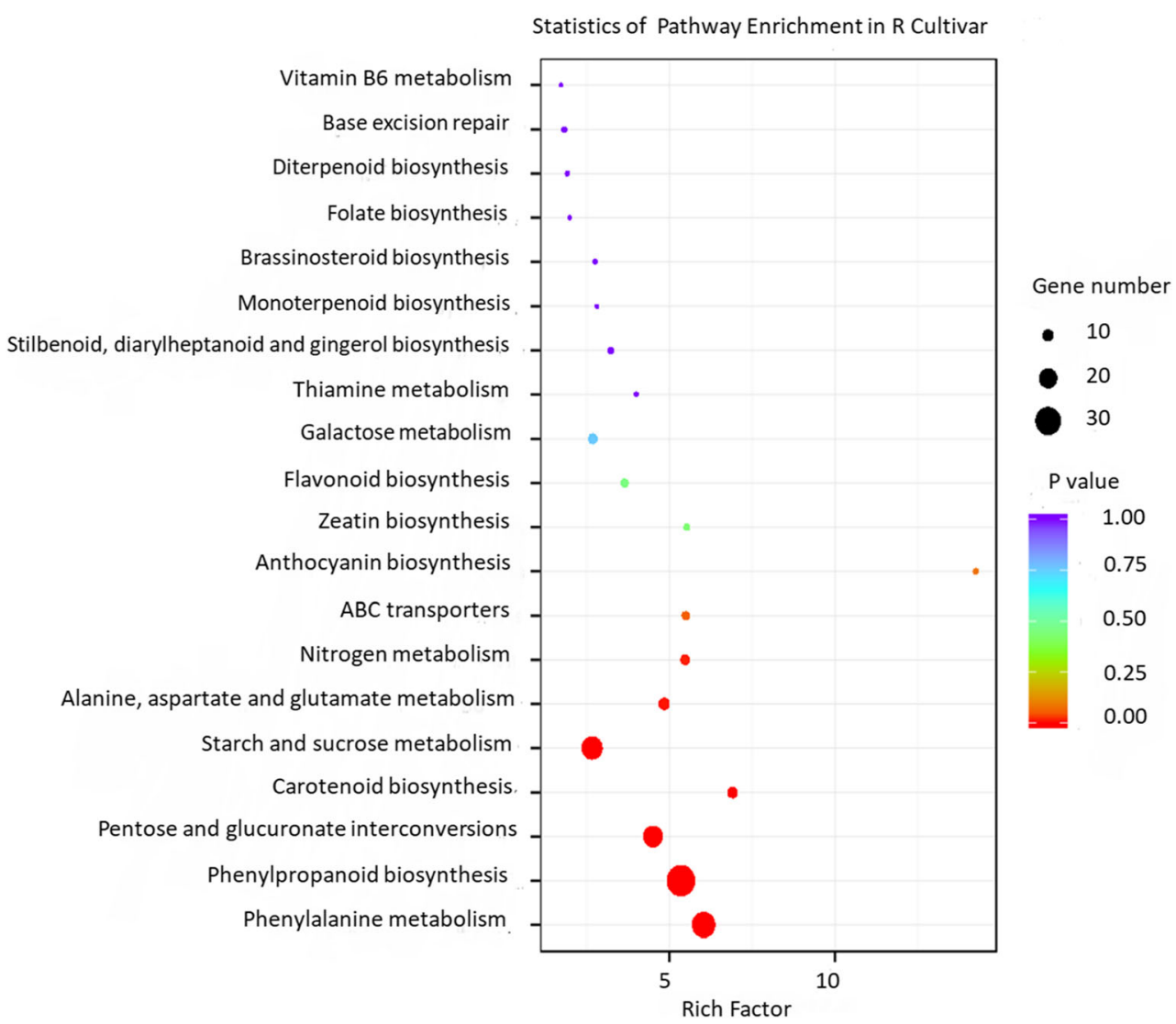

to Fov in cotton. First, we screened 1328 upregulated DEGs in cellular process, metabolic process, response to stimulus and single-organism process functional groups of classification in the resistant cultivar. Second, we screened 7 upregulated DEGs in phenylpropanoid biosynthesis (ko00940) and phenylalanine metabolism (ko00360) based on the analysis of the KEGG enrichment pathway. The result demonstrated that caffeic acid 3-O-methyltransferas e (evm.TU.Gh A09G1053) and Peroxidase 2 (evm.TU.Gh D09G1208) were significantly upregulated in the resistant cultivar, but not in the susceptible cultivar (Table 2). We found that two transcription factors MYB46

Table 1 Number of differentially expressed transcription factors in the resistant and susceptible cultivars inoculated with $F$. oxysporum

\begin{tabular}{|c|c|c|c|c|}
\hline \multirow{2}{*}{$\begin{array}{l}\mathrm{TF} \\
\text { family }\end{array}$} & \multicolumn{2}{|c|}{ Resistant cultivar } & \multicolumn{2}{|c|}{ Susceptible cultivar } \\
\hline & Upregulated & Downregulated & Upregulated & Downregulated \\
\hline AP2/ERF & 12 & 1 & 2 & 3 \\
\hline MYB & 12 & 4 & 2 & 12 \\
\hline NAC & 1 & 2 & 1 & 1 \\
\hline bHLH & 2 & 4 & 4 & 8 \\
\hline bZIP & 1 & 2 & 0 & 4 \\
\hline WRKY & 2 & 2 & 2 & 0 \\
\hline
\end{tabular}

(evm.TU.Gh_D 13 G2261) and MYB86 (evm.TU.Gh_D08G1266) were involved in resistance. Among 1328 upregulated DEGs in cellular process, metabolic process, response to stimulus, and single-organism process functional groups, 24 TFs belong to MYB family in the resistant cultivar. MYB46 (evm.TU.Gh D13G2261) and MYB86 (evm.TU.Gh_D08G1266) were uniquely upregulated in the resistant cultivar, but not in the susceptible cultivar (Table 2). When the gene expression levels were normalized to the susceptible cultivar at $0 \mathrm{~h}$, a relative high expression level of caffeic acid 3-O-methyltransferase, Peroxidase 2, MYB46 and MYB86 genes were observed in the resistant cultivar treated with Fov (Table 2). No major shifts in expression levels of these genes were observed in the susceptible cultivar (Table 2) Interestingly, these two genes and two transcription factors are involved in the process of lignin synthesis, the activation of peroxidase activity, and the positive regulation of secondary cell wall biogenesis in GO second level annotation. This indicates that lignin synthesis may play potential roles in defending against Fov.

\section{POD Activity and Lignin Content of Cotton Inoculated by Fov}

There was no significant difference of lignin concentration in the resistant cultivar treated with Fov $(72.8 \mu \mathrm{g} / \mathrm{L})$ or distilled 
Table 2 Comparisons of the relative expression pattern of four genes related to lignin synthesis in the resistant and susceptible cultivars

\begin{tabular}{|c|c|c|c|c|c|c|c|c|c|}
\hline \multirow[t]{3}{*}{ Gene ID } & \multirow[t]{3}{*}{ Gene name } & \multicolumn{4}{|c|}{ Resistant cultivar } & \multicolumn{4}{|c|}{ Susceptible cultivar } \\
\hline & & \multicolumn{4}{|c|}{ Relative expression level } & \multicolumn{4}{|c|}{ Relative expression level } \\
\hline & & $12 \mathrm{~h}$ & $24 \mathrm{~h}$ & $48 \mathrm{~h}$ & $96 \mathrm{~h}$ & $12 \mathrm{~h}$ & $24 \mathrm{~h}$ & $48 \mathrm{~h}$ & $96 \mathrm{~h}$ \\
\hline evm.TU.Gh_A09G1053 & caffeic acid 3-O-methyltransferase & 3.2 & 8.0 & 4.7 & 4.5 & 1.1 & 0.9 & 0.9 & 1.0 \\
\hline evm.TU.Gh_D09G1208 & Peroxidase 2 & 6.7 & 7.1 & 3.1 & 2.8 & 0.9 & 0.9 & 1.1 & 0.8 \\
\hline evm.TU.Gh_D13G2261 & MYB46 & 3.8 & 9.8 & 5.3 & 3.4 & 1.2 & 0.8 & 1.0 & 1.1 \\
\hline evm.TU.Gh_D08G1266 & MYB86 & 3.9 & 2.9 & 3.7 & 3.5 & 0.8 & 1.0 & 1.2 & 1.0 \\
\hline
\end{tabular}

water $(67.8 \mu \mathrm{g} / \mathrm{L})$ at $0 \mathrm{~h}$. The lignin concentration of Fov treatments increased to $89.4 \mu \mathrm{g} / \mathrm{L}, 101.8 \mu \mathrm{g} / \mathrm{L}, 98.8 \mu \mathrm{g} / \mathrm{L}$ and 106 $\mu \mathrm{g} / \mathrm{L}$ at $12 \mathrm{~h}, 24 \mathrm{~h}, 48 \mathrm{~h}$ and $96 \mathrm{~h}$, respectively. The lignin concentration showed a statistically significant change between $12 \mathrm{~h}$ and $>24 \mathrm{~h}$ timepoints $(P<0.01)$ in the resistant cultivar inoculated with Fov. Although the lignin concentration increased with the relative expression level of four genes, no strong correlation $(P<0.05)$ was found between lignin concentration with caffeic acid 3-O-methyltransferase $(\mathrm{r}=$
$0.514)$, Peroxidase $2(\mathrm{r}=0.526)$, MYB46 $(\mathrm{r}=0.221)$ and MYB86 $(\mathrm{r}=0.609)$ genes. The lignin concentration of distilled water treatments was $70.3 \mu \mathrm{g} / \mathrm{L}, 75.5 \mu \mathrm{g} / \mathrm{L}, 76.9 \mu \mathrm{g} / \mathrm{L}$ and $82.7 \mu \mathrm{g} / \mathrm{L}$ at $12 \mathrm{~h}, 24 \mathrm{~h}, 48 \mathrm{~h}$ and $96 \mathrm{~h}$, respectively. The concentration of lignin in the Fov treatment was significantly higher than that in the water treatments (Fig. 5A). In the susceptible cultivar, the lignin concentration of distilled water treatments was $68 \mu \mathrm{g} / \mathrm{L}, 70.9 \mu \mathrm{g} / \mathrm{L}, 77.8 \mu \mathrm{g} / \mathrm{L}, 78.9 \mu \mathrm{g} / \mathrm{L}$ and $83.9 \mu \mathrm{g} / \mathrm{L}$ at $0 \mathrm{~h}, 12 \mathrm{~h}, 24 \mathrm{~h}, 48 \mathrm{~h}$ and $96 \mathrm{~h}$, respectively.
A

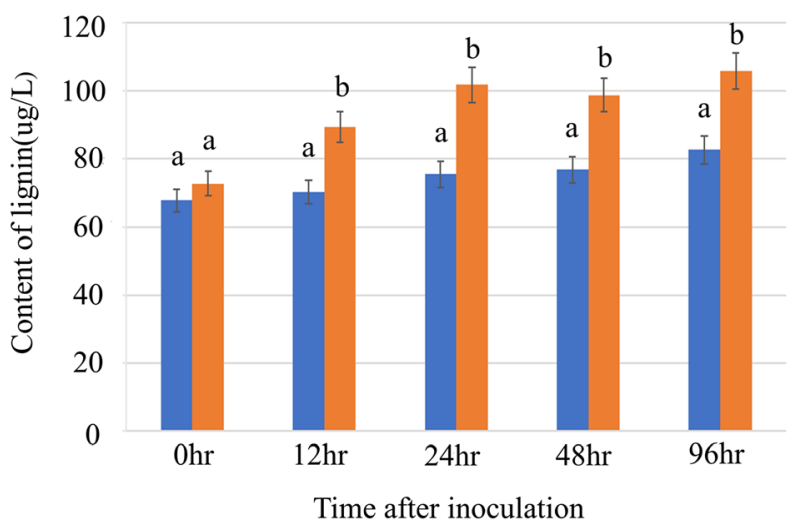

C

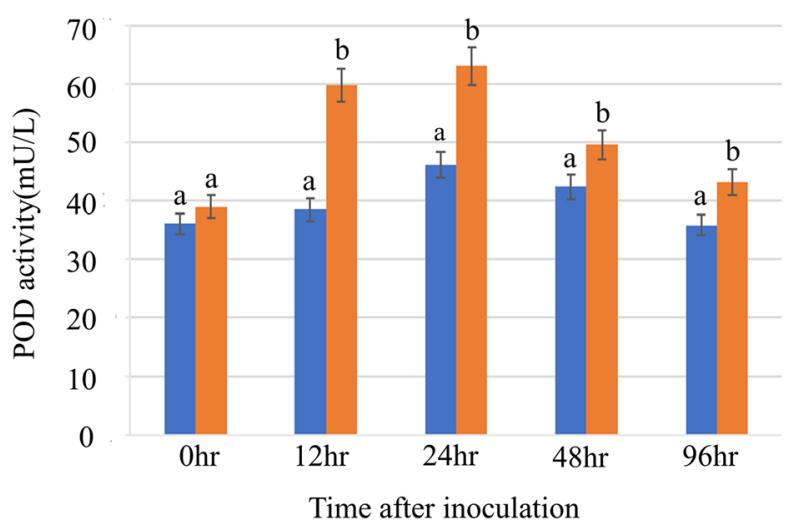

Fig. 5 Lignin concentration and peroxidase activity in the Yumian21 resistant cultivar (A and C) and Jimian11 susceptible cultivar (B and D) inoculated with $F$. oxysporum and distilled water. The error bars represent
B

SCK

SI

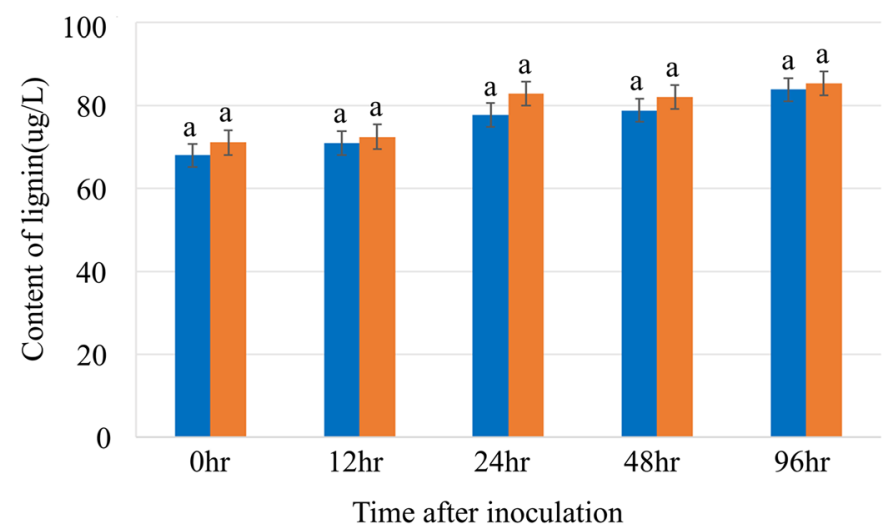

D $\square \mathrm{SCK} \square \mathrm{SI}$

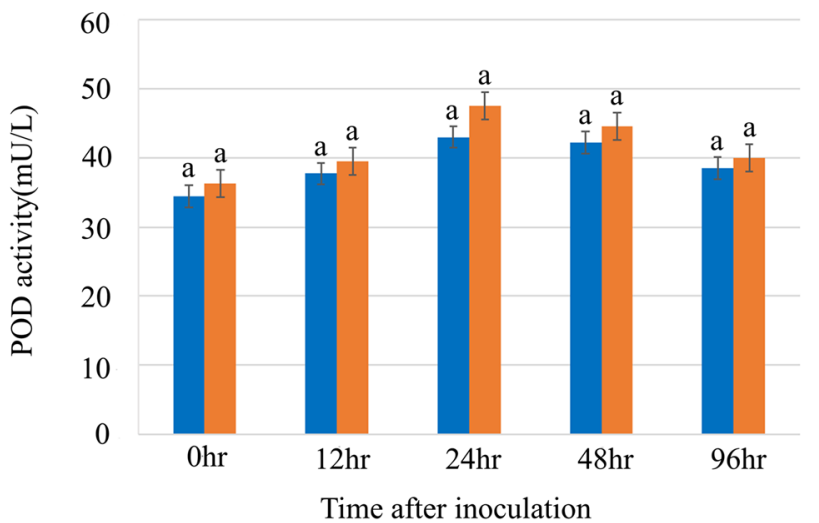

the standard deviation (SD) of lignin content or peroxidase activity in response to infection at $0 \mathrm{~h}, 12 \mathrm{~h}, 24 \mathrm{~h}, 48 \mathrm{~h}$, and $96 \mathrm{~h}$ after mock- and F. oxysporum - inoculation 
The lignin concentration of Fov treatments was $71.1 \mu \mathrm{g} / \mathrm{L}$, $72.5 \mu \mathrm{g} / \mathrm{L}, 83 \mu \mathrm{g} / \mathrm{L}, 82.1 \mu \mathrm{g} / \mathrm{L}$ and $85.4 \mu \mathrm{g} / \mathrm{L}$ at $0 \mathrm{~h}, 12 \mathrm{~h}$, $24 \mathrm{~h}, 48 \mathrm{~h}$ and $96 \mathrm{~h}$, respectively (Fig. 5B). No significant change was found in the susceptible cultivar treated with distilled water or Fov.

As one of the key enzymes in the antioxidant system in plants, peroxidase (POD) plays an important role in the immune defense mechanism, and its expression is induced by fungi. At the same time, it is also an important control enzyme in the lignin synthesis pathway. In this research, there was no significant difference of POD activity in the resistant cultivar treated with Fov $(39 \mathrm{mU} / \mathrm{L})$ or distilled water $(36.1 \mathrm{mU} / \mathrm{L})$ before Fov inoculation. The POD activity of Fov treatments increased to $59.8 \mathrm{mU} / \mathrm{L}, 63.1 \mathrm{mU} / \mathrm{L}, 49.6 \mathrm{mU} / \mathrm{L}$ and $43.2 \mathrm{mU} /$ $\mathrm{L}$ at $12 \mathrm{~h}, 24 \mathrm{~h}, 48 \mathrm{~h}$ and $96 \mathrm{~h}$, respectively. In the resistant cultivar inoculated with Fov, the POD activity showed a statistically significant change over $12 \mathrm{~h}, 24 \mathrm{~h}, 48 \mathrm{~h}$ and $96 \mathrm{~h}$ timepoints $(\mathrm{P}<0.01)$ and it reached the highest level at $24 \mathrm{~h}$. The relative expression level of Peroxidase 2 gene was highly correlated with the POD activity $(\mathrm{r}=0.969, \mathrm{P}<0.05)$ The POD activity of distilled water treatments was $38.5 \mathrm{mU} / \mathrm{L}$, $46.1 \mathrm{mU} / \mathrm{L}, 42.4 \mathrm{mU} / \mathrm{L}$ and $35.8 \mathrm{mU} / \mathrm{L}$ at $12 \mathrm{~h}, 24 \mathrm{~h}, 48 \mathrm{~h}$ and $96 \mathrm{~h}$, respectively. The activity of POD in the Fov treatment was significantly higher than that in the distilled water treatments (Fig. 5C). In the susceptible cultivar, The POD activity of distilled water treatments was $34.4 \mathrm{mU} / \mathrm{L}$, $37.7 \mathrm{mU} / \mathrm{L}, 43 \mathrm{mU} / \mathrm{L}, 42.2 \mathrm{mU} / \mathrm{L}$ and $38.5 \mathrm{mU} / \mathrm{L}$ at $0 \mathrm{~h}$, $12 \mathrm{~h}, 24 \mathrm{~h}, 48 \mathrm{~h}$ and $96 \mathrm{~h}$, respectively. The POD activity of Fov treatments was $36.3 \mathrm{mU} / \mathrm{L}, 39.5 \mathrm{mU} / \mathrm{L}, 47.5 \mathrm{mU} / \mathrm{L}$, $44.6 \mathrm{mU} / \mathrm{L}$ and $40 \mathrm{mU} / \mathrm{L}$ at $0 \mathrm{~h}, 12 \mathrm{~h}, 24 \mathrm{~h}, 48 \mathrm{~h}$ and $96 \mathrm{~h}$, respectively (Fig. 5D). No significant change was observed in the susceptible cultivar treated with distilled water or Fov.

\section{Discussion}

We found 1055 DEGs in the resistant cultivar and 995 DEGs in the susceptible cultivar. The global gene expression in the resistant cultivar is stronger than that in the susceptible cultivar. Interestingly, more downregulated genes were identified than upregulated genes in both cultivars after inoculation by Fov. Xu et al. found the same pattern with cotton inoculated with Verticillium wilt (Xu et al. 2011). However, the proportion of downregulated genes in the resistant cultivar $(55 \%)$ was less than that in the susceptible cultivar $(63 \%)$. Although the developmental processes of two cultivars were all affected by Fov invasion, the resistant cultivar was less affected than the susceptible cultivar.

GO classification showed that cellular process, singleorganism process, metabolic process and response to stimulus were the main enriched GO terms of the biological process group and all of them were involved in response to Fov infection. By further analysis of the KEGG pathway, we found that in both cultivars the most significantly enriched KEGG pathways were "phenylpropanoid biosynthesis," followed by "phenylalanine metabolism." This indicates that these pathways are the key metabolic pathways in cotton in response to FW. Phenylpropanoids can function as inducible antimicrobial compounds as well as signaling molecules in plantpathogen responses (Dixon 2001; Naoumkina et al. 2010). Phenylpropanoid metabolism has been well documented as the most important plant metabolic pathway during plant defense against biotic stress (Cass et al. 2015; La Camera et al. 2004). The phenylpropanoid pathway contains multiple branches, and lignin biosynthesis is a downstream branch of this pathway; specifically, the pathway synthesizes monolignols, which are substrates of lignin polymerization (Boerjan et al. 2003; Mottiar et al. 2016). In resistant cotton, genes involved in the phenylpropanoid pathway and lignin accumulation were significantly induced after $V$. dahliae infection (Xu et al. 2011). Overexpression of GhLacl and GhLac15, genes related to phenylpropanoid pathway and lignin biosynthesis, was found to enhance $V$. dahliae resistance (Hu et al. 2018; Zhang et al. 2018; Zhang et al. 2019). Consistently, we found that genes in the "phenylpropanoid biosynthesis" pathway can promote lignin biosynthesis, therefore enhancing cotton resistance to Fov.

Plant defense-associated genes are normally regulated by transcription factors. TFs can coordinate and control the activity of multiple stress response genes and establish a complex regulatory network to regulate physiological and metabolic responses to cope with disease stress (Buscaill and Rivas 2014; Nakashima et al. 2009). Our results indicate that six TF families (AP2/ERF, MYB, NAC, bHLH, bZIP and WRKY) are activated in cotton plants following Fov infection. In $A$. thaliana, the majority of $F$. oxysporum-responsive TFs also belong to the ERF, MYB, NAC, bHLH, and WRKY families (Zhu et al. 2012). Studies showed that MYB genes are involved in a plant's response to stress, such as drought and cold and pathogen (Erpen et al. 2018; Liu et al. 2016). When cotton plants were infected by Fov, most of the MYB genes were upregulated in the resistant cultivar but downregulated in the susceptible cultivar. MYB families may play a potential role in the regulation of defense gene expression when upland cotton is attacked by Fov.

Lignin may play a key role in cotton resistance to Fov. Physiological and biochemical studies have shown that the Fusarium-resistant watermelon varieties have strong cell structures, such as thickened xylem, to prevent entry of the pathogen (Tang et al. 2019a). As the major end product of the phenylpropanoid pathway, lignin is essential in the formation of cell walls, which forms a physical barrier that increase the resistance to pathogen infection. Caffeic acid $O$ methyltransferase is a methylase in the lignin specific pathway. It catalyzes the multi-step methylation of hydroxylated monomer lignin precursor and plays a major role in lignin 
biosynthesis (O'Malley et al. 1993). Two genes, caffeic acid 3O-methyltransferase (evm.TU.Gh_A09G1053) and Peroxidase 2 (evm.TU.Gh_D09G1208), were found upregulated in the resistant cotton cultivar but not in the susceptible cultivar. Strong downregulation of caffeic acid 3-Omethyltransferase decrease lignin content in Alfalfa (Guo et al. 2001), maize (Pichon et al. 2006) and Leucaena (Rastogi and Dwivedi 2006). Peroxidase helps polymerize monolignols into lignin and enhances cell wall during pathogen attack and damage (Marjamaa et al. 2009). Gayoso et al. found that POD activity was upregulated in a resistant tomato cultivar infected by Verticillium wilt (Gayoso et al. 2010). As a key gene in lignin synthesis, the peroxidase 2 (evm.TU.Gh_D09G1208) coding gene was activated and upregulated in resistant cotton during Fov infection. Transcription factors can also regulate lignin synthesis, for example: the R2R3-MYB transcription factor regulates lignin biosynthesis through binding to the AC element (Rogers et al. 2005), which exists in the promoter region of gene in most phenylpropanoid pathways (Hatton et al. 1995). We found that transcription factors MYB46 (evm.TU.Gh_D13G2261) and MYB86 (evm.TU.Gh_D08G1266) were upregulated in the resistant cultivar, but not in the susceptible cultivar. Among transcription factors regulating phenylpropanoid and lignin biosynthesis, MYB46 and MYB86 are transcriptional activators of the lignin biosynthetic pathway during secondary cell wall formation in Arabidopsis (Taylor-Teeples et al. 2015; Zhong et al. 2007). In this study, DEGs analysis showed that two genes related to lignin biosynthesis and two transcription factors were upregulated in the resistant cotton cultivar. These observations were also confirmed by qRT-PCR analysis. However, the defense response of plant to biotic stress is a systematic network, which involves many pathways and genes (Dangl and Jones 2001). Lignin synthesis is related to many genes controlling a few pathways, not only two genes and two TF. We believe other pathways and genes may also play important roles in the cotton immune defense mechanism to Fov invasion.

Based on DEG analysis, GO classification, KEGG enrichment, and TFs analysis, we concluded that lignin is possibly involved in upland cotton's response to FW. To further confirm this, we measured POD activity and lignin content before and after $F$. oxysporum inoculation in the resistant cultivar and susceptible cultivars. Results showed that both POD activity and lignin content were significantly induced in the resistant cotton.

Breeding and utilizing FW-resistant cotton cultivars has proven to be the most cost-effective control method for this disease. Lignin related genes could be good targets for cotton disease resistance breeding. Lignin content of crops could also be modified by transgenic approaches: the manipulation of lignin biosynthesis at the regulatory level, controlling monolignol biosynthetic enzymes, or the modification of lignin polymer structure (Frei 2013). Liu et al. suggest several candidate genes for the genetic modification of lignin towards breeding rice with high lodging resistance (Liu et al. 2018). The over-expression of caffeic acid 3-O-methyltransferase (evm.TU.Gh_A09G1053) and peroxidase 2 (evm.TU.Gh D09G1208) genes would be able to facilitate the breeding of FW resistant cotton. Additionally, our data suggests the potential use of lignin quantification as a selection tool to identify FW resistant cotton. Lignin content has been used as a biochemical indicator to measure immune activation response (Adams-Phillips et al. 2010; Kishi-Kaboshi et al. 2010). High lignin concentration has been found associated with disease resistance in tomato (Mandal et al. 2013), rice (Liu et al. 2018) and soybean (Peltier et al. 2009). The near infrared spectroscopy method is a promising tool for lowcost, and high-throughput lignin analysis of a large number of samples.

\section{Materials and Methods}

\section{Plant Materials and Inoculation}

The Jimian11 susceptible cultivar has been set as the susceptible standard control in China's national cotton disease and pest resistance evaluation programs since 2009 (GB/22101.4 2009). The Yumian 21 cultivar is currently served as a resistant control to FOV in national cotton regional trials in China (Mei et al. 2014). The cultivars were delinted with sulfuric acid and sterilized with $0.1 \% \mathrm{HgCl}$ for $10-15 \mathrm{~min}$, and grown in sterilized soil (vermiculite: nutritive soil $=1: 1$ ) at $25{ }^{\circ} \mathrm{C}$ temperature, $70 \%$ relative humidity with a photoperiod $16 \mathrm{~h}$ light and $8 \mathrm{~h}$ dark. In this study, " $\mathrm{R}$ " indicates resistant cultivar Yumian21, "S" indicates susceptible cultivar Jimian11, "CK" indicates the control, and "I" indicates inoculation.

The highly aggressive strain of the defoliating fungus $F$. oxysporum was incubated on potato-dextrose agar (PDA) media for two weeks and then cut into small pieces $(1-2 \mathrm{~cm})$ before transference into $250 \mathrm{~mL}$ conical flasks containing $110 \mathrm{~mL}$ of liquid Czapek medium. Each flask containing three pieces of PDA medium with mycelia was shaken at $120 \mathrm{rpm}$ at $25^{\circ} \mathrm{C}$ for $3 \mathrm{~d}$ on a rotary shaker. The suspension liquid was adjusted to $2 \times 10^{7}$ spores per $\mathrm{mL}$ with distilled water.

Each seedling was inoculated with a $10 \mathrm{~mL} \mathrm{~F}$. oxysporum spore suspension of $2 \times 10^{7}$ spores per $\mathrm{mL}$ by watering roots at the two-true-leaf growth stage (Yao et al. 2019). Control plants were inoculated with sterile distilled water and treated in the same way. The plant roots were collected at $0,12,24$, 48 , and $96 \mathrm{~h}$ post inoculation and frozen immediately in liquid nitrogen. Samples were pooled together as a mixed infection RNA library. Three replicates were used for each treatment, and 15 plants were used in each replication. 


\section{RNA Sequencing and Data Processing}

Total RNA was extracted with an RNA prep Pure Plant Kit (TIANGEN). The RNA quality was assessed using a NanoDrop 2000 spectrophotometer (Thermo Fisher Scientific, Wilmington, DE) and Nano 6000 Assay Kit on Agilent Bioanalyzer 2100 System (Agilent Technologies, CA, USA), respectively.

RNA was fragmented randomly and rRNA was removed from the samples by using a Ribo-Zero rRNA removal kit (Epicentre, Madison, WI, USA). The cDNA was synthesized by using a random hexamer primer, and purified with AMPure XP beads (Beckman Coulter, Beverly, USA). The purified double-strand cDNA was end-repaired, poly-A tailadded, and ligated to the Illumina adapter. Clustering of the index-coded samples was performed on an acBot Cluster Generation System using TruSeq PE Cluster Kitv3-cBot-HS (Illumina) according to the manufacturer's instructions. After cluster generation, the library preparations were sequenced on an Illumina HiSeq X Ten system (Illumina Inc., USA).

The sequence alignment and subsequent analysis of the high-quality data was conducted using the designated genome Gossypium_hirsutum_v1.1 as a reference (http://mascotton. njau.edu.cn/info/1054/1118.htm) via HISAT (Li et al. 2014), while StringTie (Kim et al. 2015) was used to assemble the reads that had been mapped to the designated genome. Based on the selected reference genome sequences, the mapped reads were spliced by StringTie and compared with the original annotation information of the genome to find the previously unannotated transcription regions. In order to obtain annotation information using BLAST software, the mapped reads were also compared to the following databases: the Nonredundant (Nr) (Sayers et al. 2019), Swiss-Prot (Apweiler et al. 2004), Gene Ontology(GO) (Ashburner et al. 2000), Cluster of Orthologous Groups of proteins (COG) (Tatusov et al. 2000), Evolutionary Genealogy of Genes: Nonsupervised Orthologous Groups(EggNOG), Eukaryotic Orthologous Groups (KOG) (Koonin et al. 2004), and Kyoto Encyclopedia of Genes and Genomes (KEGG) (Kanehisa et al. 2004). The FPKM method was used to indicate the transcriptional or gene expression level (Trapnell et al. 2010). The FPKM value was calculated as follows: FPKM = cDNA fragments/ (mapped fragments (millions) X transcript length $(\mathrm{kb})$, with cDNA fragments being the number of reads that aligned to a specific unigene, mapped fragments being the total number of reads that aligned to all unigenes, and transcript length being the length of the unigene.

\section{Identification of Differentially Expressed Genes (DEG) and Data Validation}

The DEGs between the inoculated and control samples were identified by edgeR (Robinson et al. 2009). The FC value indicates the ratio of expression between two samples (groups). The false discovery rate (FDR) control method was applied in multiple hypothesis testing to correct the $P$ value. An FDR $<0.05$ and $\mathrm{FC}=1.5$ were set as the thresholds for assessing the significance of the difference in gene expression (Reiner et al. 2003).

The level of gene expression obtained by RNA-Seq was verified using quantitative real-time PCR (qRT-PCR). The primer sequences were designed using Primer3 (http:// bioinfo.ut.ee/primer3/) and synthesized by the Beijing Genomics Institute (BGI, Beijing, China). The qRT-PCR was carried out with three technical replicates using NovoStart SYBR qPCR Super Mix Plus Kit (Novoprotein) on an Eppendorf Mastercycler ep realplex machine (Germany) according to the manufacturer's protocol. PCR cycles were as follows: one cycle of $1 \mathrm{~min}$ at $95^{\circ} \mathrm{C}$, followed by 40 cycles at $95^{\circ} \mathrm{C}$ for $20 \mathrm{~s}, 60^{\circ} \mathrm{C}$ for $20 \mathrm{~s}$ and $95^{\circ} \mathrm{C}$ for $30 \mathrm{~s}$. Following amplification, all products were subjected to melt curve analysis. The cotton UBQ7 gene (GenBank: DQ116441) was used as the reference gene to normalize the total amount of $500 \mathrm{ng}$ RNA in each reaction.

\section{Measurement of Peroxidase and Lignin}

The peroxidase activity (POD) and lignin content were measured by using an enzyme-linked immunosorbent assay (ELISA) kit (Shanghai Bio-Tech Company, Ltd) according to the manufacturer's instructions (Kapat and Dey 2000; Lequin 2005). Briefly, blank controls, standard wells, and sample wells were set up. A $50 \mu$ l of the ELISA-coated reference standard $40 \mu \mathrm{l}$ of sample replacement solution and $10 \mu \mathrm{l}$ of the test sample were used. The solutions were gently mixed and incubated at $37^{\circ} \mathrm{Cfor} 45 \mathrm{~min}$. Each well was washed five times using washing buffer. Samples were incubated with $50 \mu \mathrm{L}$ Biotinylated anti-IgG at $37^{\circ} \mathrm{C}$ for $30 \mathrm{~min}$; then incubated with $50 \mu \mathrm{L}$ streptavidin-HRP at $37^{\circ} \mathrm{C}$ for $15 \mathrm{~min}$. A total of $50 \mathrm{uL}$ chromogen solution A and $\mathrm{B}$ solutions were added each well and incubate samples at $37^{\circ} \mathrm{Cfor} 15 \mathrm{~min}$. The reactions were stopped by adding $50 \mu \mathrm{L}$ stop solution. The optical density (OD) values were measured at $450 \mathrm{~nm}$ for the standard curve. The data were collected from three replicated plants at $0 \mathrm{~h}, 12 \mathrm{~h}, 24 \mathrm{~h}, 48 \mathrm{~h}$ and $96 \mathrm{~h}$ after inoculation. The analysis of variance (ANOVA), and all significant differences were examined according to Tukey test by DPS 6.05 software at $p<0.05$ (Zhejiang University, Hangzhou, China) (Tang and Zhang 2013).

\section{Histochemical Test}

Hand-cut cross-sections were made from the base of the stem of both the Fov and distilled water treated cotton plants at $16 \mathrm{~d}$ after treatment. Lignin histochemistry was examined using 
safranin O-fast green staining method (Jia et al. 2015). The materials were fixed in 50\% FAA for $24 \mathrm{~h}$ then dehydrated with ethanol, and embedded in paraffin. The $4 \mu \mathrm{m}$ thickness cut sections were stained with $1 \%$ safranin $\mathrm{O}$ in distilled water (pH 6.7) for $10 \mathrm{~min}$ then washed and counterstained with a $0.1 \%$ solution of fast green in water for $5 \mathrm{~min}$. Tissue sections with lignin were stained and observed under a light microscope (LEICA CTR6000 Germany). The presence of lignin was stained with red.

Supplementary Information The online version contains supplementary material available at https://doi.org/10.1007/s12042-020-09278-9.

Acknowledgments This study was supported by the Cotton Industry Technology System of China (Grant no. CARS-18-04), the Natural Science Foundation of China (NSFC grant No. U1304319), National Key Research and Development Projects of Project of China (Grant no. 2018YFD0100305), National transgenic major projects of China (2016ZX08005-001-005);(2016ZX08005-005).

Authors' Contributions Weiping Fang, Jianan Hou and Deyi Xie contributed to the study conception and design. Material preparation, data collection and analysis were performed by Jianan Hou, Fu'an Zhao, Wu Li, Yajing Zhu, Yao Sun, Shuping Lv, Lihong Nie, Mengmeng Wang, Xiaopei Bo, Zhongjie Tang, Yuanming Zhao, and Qianwen Zhan. The first draft of the manuscript was written by Jianan Hou and Xiaojie Yang revised the manuscript. All authors commented on previous versions of the manuscript. All authors read and approved the final manuscript.

\section{Compliance with Ethical Standards}

Conflict of Interest There are no conflicts of interest

Research Involving Human and Animal Rights The research does not involve human and/or animal experimentation.

Open Access This article is licensed under a Creative Commons Attribution 4.0 International License, which permits use, sharing, adaptation, distribution and reproduction in any medium or format, as long as you give appropriate credit to the original author(s) and the source, provide a link to the Creative Commons licence, and indicate if changes were made. The images or other third party material in this article are included in the article's Creative Commons licence, unless indicated otherwise in a credit line to the material. If material is not included in the article's Creative Commons licence and your intended use is not permitted by statutory regulation or exceeds the permitted use, you will need to obtain permission directly from the copyright holder. To view a copy of this licence, visit http://creativecommons.org/licenses/by/4.0/.

\section{References}

Adams-Phillips L, Briggs AG, Bent AF (2010) Disruption of poly(ADPribosyl)ation mechanisms alters responses of Arabidopsis to biotic stress. Plant Physiol 152(1):267-280. https://doi.org/10.1104/pp. 109.148049

Akhunov AA, Golubenko Z, Khashimova NR, Mustakimova EC, Vshivkov SO (2008) Role of chitin-specific peroxidase in wiltresistant cotton. Chem Nat Compd 44(4):493-496. https://doi.org/ 10.1007/s10600-008-9104-1
Apweiler R, Bairoch A, Wu CH et al (2004) UniProt: the universal protein knowledgebase. Nucleic Acids Res 32(Database issue):D115D119. https://doi.org/10.1093/nar/gkh131

Ashburner M, Ball CA, Blake JA, Botstein D, Butler H, Cherry JM, Davis AP, Dolinski K, Dwight SS, Eppig JT, Harris MA, Hill DP, Issel-Tarver L, Kasarskis A, Lewis S, Matese JC, Richardson JE, Ringwald M, Rubin GM, Sherlock G (2000) Gene ontology: tool for the unification of biology. Nat Genet 25(1):25-29. https://doi.org/ $10.1038 / 75556$

Assigbetse K, Fernandez D, Dubois M-P et al (1994) Differentiation of Fusarium oxysporum $f$. sp. vasinfectum races on cotton by random amplified polymorphic DNA (RAPD) analysis. Phytopathology 84(6):622-626. https://doi.org/10.1094/Phyto-84-622

Boerjan W, Ralph J, Baucher M (2003) Lignin biosynthesis. Annu Rev Plant Biol 54(1):519-546. https://doi.org/10.1146/annurev.arplant. 54.031902 .134938

Bonello P, Blodgett JT (2003) Pinus nigra-Sphaeropsis sapinea as a model pathosystem to investigate local and systemic effects of fungal infection of pines. Physiol Mol Plant Pathol 63(5):249-261. https://doi.org/10.1016/j.pmpp.2004.02.002

Buscaill P, Rivas S (2014) Transcriptional control of plant defence responses. Curr Opin Plant Biol 20:35-46. https://doi.org/10.1016/j. pbi.2014.04.004

Cass CL, Peraldi A, Dowd PF, Mottiar Y, Santoro N, Karlen SD, Bukhman YV, Foster CE, Thrower N, Bruno LC, Moskvin OV, Johnson ET, Willhoit ME, Phutane M, Ralph J, Mansfield SD, Nicholson P, Sedbrook JC (2015) Effects of PHENYLALANINE AMMONIA LYASE (PAL) knockdown on cell wall composition, biomass digestibility, and biotic and abiotic stress responses in Brachypodium. J Exp Bot 66(14):4317-4335. https://doi.org/10. 1093/jxb/erv269

Chisholm ST, Coaker G, Day B, Staskawicz BJ (2006) Host-microbe interactions: shaping the evolution of the plant immune response. Cell 124(4):803-814. https://doi.org/10.1016/j.cell.2006.02.008

Cianchetta AN, Davis RM (2015) Fusarium wilt of cotton: management strategies. Crop Prot 73:40-44. https://doi.org/10.1016/j.cropro. 2015.01.014

Dangl JL, Jones JDG (2001) Plant pathogens and integrated defence responses to infection. Nature 411(6839):826-833. https://doi.org/ $10.1038 / 35081161$

Dixon RA (2001) Natural products and plant disease resistance. Nature 411(6839):843-847. https://doi.org/10.1038/35081178

Dowd C, Wilson IW, McFadden H (2004) Gene expression profile changes in cotton root and hypocotyl tissues in response to infection with Fusarium oxysporum $f$. $s p$. vasinfectum. Mol Plant-Microbe Interact 17(6):654-667. https://doi.org/10.1094/mpmi.2004.17.6. 654

Erpen L, Devi HS, Grosser JW, Dutt M (2018) Potential use of the DREB/ERF, MYB, NAC and WRKY transcription factors to improve abiotic and biotic stress in transgenic plants. Plant Cell, Tissue and Organ Cult 132(1):1-25. https://doi.org/10.1007/s11240-0171320-6

Frei M (2013) Lignin: characterization of a multifaceted crop component. Sci World J 2013:436517-436525. https://doi.org/10.1155/2013/ 436517

Gayoso C, Pomar F, Novo-Uzal E, Merino F, Martínez de Ilárduya Ó (2010) The Ve-mediated resistance response of the tomato to Verticillium dahliae involves $\mathrm{H}_{2} \mathrm{O}_{2}$, peroxidase and lignins and drives $P A L$ gene expression. BMC Plant Biol 10(1):232. https:// doi.org/10.1186/1471-2229-10-232

Guo D, Chen F, Inoue K, Blount JW, Dixon RA (2001) Downregulation of caffeic acid 3-O-methyltransferase and caffeoyl CoA 3-OMethyltransferase in transgenic alfalfa: impacts on lignin structure and implications for the biosynthesis of $\mathrm{G}$ and $\mathrm{S}$ lignin. Plant Cell 13(1):73-88. https://doi.org/10.1105/tpc.13.1.73 
Guo W, Jin L, Miao Y, He X, Hu Q, Guo K, Zhu L, Zhang X (2016) An ethylene response-related factor, GbERF1-like, from Gossypium barbadense improves resistance to Verticillium dahliae via activating lignin synthesis. Plant Mol Biol 91(3):305-318. https://doi.org/ 10.1007/s11103-016-0467-6

Hall C, Heath R, Guest DI (2011) Rapid and intense accumulation of terpenoid phytoalexins in infected xylem tissues of cotton (Gossypium hirsutum) resistant to Fusarium oxysporum f.sp. vasinfectum. Physiol Mol Plant Pathol 76(3):182-188. https://doi. org/10.1016/j.pmpp.2011.09.002

Hatton D, Sablowski R, Yung M-H, Smith C, Schuch W, Bevan M (1995) Two classes of cis sequences contribute to tissue-specific expression of a PAL2 promoter in transgenic tobacco. Plant J 7(6): 859-876. https://doi.org/10.1046/j.1365-313X.1995.07060859.x

Hu Q, Min L, Yang X, Jin S, Zhang L, Li Y, Ma Y, Qi X, Li D, Liu H, Lindsey K, Zhu L, Zhang X (2018) Laccase GhLacl modulates broad-spectrum biotic stress tolerance via manipulating phenylpropanoid pathway and jasmonic acid synthesis. Plant Physiol 176(2):1808-1823. https://doi.org/10.1104/pp.17.01628

Hückelhoven R (2007) Cell wall-associated mechanisms of disease resistance and susceptibility. Annu Rev Phytopathol 45(1):101-127. https://doi.org/10.1146/annurev.phyto.45.062806.094325

Jia X, Wang G, Xiong F et al (2015) De novo assembly, transcriptome characterization, lignin accumulation and anatomic characteristics: novel insights into lignin biosynthesis during celery leaf development. Sci Rep 5:8259. https://doi.org/10.1038/srep08259

Jones JDG, Dangl JL (2006) The plant immune system. Nature 444(7117):323-329. https://doi.org/10.1038/nature05286

Kanehisa M, Goto S, Kawashima S et al (2004) The KEGG resource for deciphering the genome. Nucleic Acids Res 32(Database issue): D277-D280. https://doi.org/10.1093/nar/gkh063

Kapat A, Dey S (2000) An alternative approach to the detection of lignin: a note on the application of ELISA using polyclonal antibodies. Bioprocess Eng 22(2000):75-77. https://doi.org/10.1007/ PL00009105

Kawasaki T, Koita H, Nakatsubo T, Hasegawa K, Wakabayashi K, Takahashi H, Umemura K, Umezawa T, Shimamoto K (2006) Cinnamoyl-CoA reductase, a key enzyme in lignin biosynthesis, is an effector of small GTPase Rac in defense signaling in rice. Proc Natl Acad Sci U S A 103(1):230-235. https://doi.org/10.1073/pnas. 0509875103

Kim D, Langmead B, Salzberg SL (2015) HISAT: a fast spliced aligner with low memory requirements. Nat Methods 12(4):357-360. https://doi.org/10.1038/nmeth.3317

Kishi-Kaboshi M, Okada K, Kurimoto L, Murakami S, Umezawa T, Shibuya N, Yamane H, Miyao A, Takatsuji H, Takahashi A, Hirochika H (2010) A rice fungal MAMP-responsive MAPK cascade regulates metabolic flow to antimicrobial metabolite synthesis. Plant J 63(4):599-612. https://doi.org/10.1111/j.1365-313X.2010. 04264.x

Koonin EV, Fedorova ND, Jackson JD, Jacobs AR, Krylov DM, Makarova KS, Mazumder R, Mekhedov SL, Nikolskaya AN, Rao B, Rogozin IB, Smirnov S, Sorokin AV, Sverdlov AV, Vasudevan S, Wolf YI, Yin JJ, Natale DA (2004) A comprehensive evolutionary classification of proteins encoded in complete eukaryotic genomes. Genome Biol 5(2):1-28. https://doi.org/10.1186/gb-20045-2-r7

La Camera S, Gouzerh G, Dhondt S et al (2004) Metabolic reprogramming in plant innate immunity: the contributions of phenylpropanoid and oxylipin pathways. Immunol Rev 198(1): 267-284. https://doi.org/10.1111/j.0105-2896.2004.0129.x
Lequin RM (2005) Enzyme immunoassay (EIA)/enzyme-linked Immunosorbent assay (ELISA). Clin Chem 51:2415-2418. https:// doi.org/10.1373/clinchem.2005.051532

Li J, Ma W, Zeng P, Wang J, Geng B, Yang J, Cui Q (2014) LncTar: a tool for predicting the RNA targets of long noncoding RNAs. Brief Bioinform 16(5):806-812. https://doi.org/10.1093/bib/bbu048

Liu H, Guo Z, Gu F, Ke S, Sun D, Dong S, Liu W, Huang M, Xiao W, Yang G, Liu Y, Guo T, Wang H, Wang J, Chen Z (2017) 4Coumarate-CoA ligase-like gene $O S A A E 3$ negatively mediates the rice blast resistance, floret development and lignin biosynthesis. Front Plant Sci 7(2041). https://doi.org/10.3389/fpls.2016.02041

Liu S, Huang Y, Xu H, Zhao M, Xu Q, Li F (2018) Genetic enhancement of lodging resistance in rice due to the key cell wall polymer lignin, which affects stem characteristics. Breed Sci 68(5):508-515. https:// doi.org/10.1270/jsbbs. 18050

Liu Z, Luan Y, Li J, Yin Y (2016) Expression of a tomato MYB gene in transgenic tobacco increases resistance to Fusarium oxysporum and Botrytis cinerea. Eur J Plant Pathol 144(3):607-617. https://doi.org/ 10.1007/s10658-015-0799-0

Malinovsky FG, Fangel JU, Willats WGT (2014) The role of the cell wall in plant immunity. Front Plant Sci 5(178). https://doi.org/10.3389/ fpls.2014.00178

Mandal S, Kar I, Mukherjee AK, Acharya P (2013) Elicitor-induced defense responses in Solanum lycopersicum against Ralstonia solanacearum. ScientificWorldJournal 2013:561056-561059. https://doi.org/10.1155/2013/561056

Marjamaa K, Kukkola EM, Fagerstedt KV (2009) The role of xylem class III peroxidases in lignification. J Exp Bot 60(2):367-376. https:// doi.org/10.1093/jxb/ern278

Mei H, Ai N, Zhang X, Ning Z, Zhang T (2014) QTLs conferring FOV 7 resistance detected by linkage and association mapping in upland cotton. Euphytica 197(2):237-249. https://doi.org/10.1007/s10681014-1063-y

Mellon JE, Dowd MK, Beltz SB, Moore GG (2014) Growth inhibitory effects of gossypol and related compounds on fungal cotton root pathogens. Lett Appl Microbiol 59(2):161-168. https://doi.org/10. 1111/lam. 12262

Mottiar Y, Vanholme R, Boerjan W, Ralph J, Mansfield SD (2016) Designer lignins: harnessing the plasticity of lignification. Curr Opin Biotechnol 37:190-200. https://doi.org/10.1016/j.copbio. 2015.10.009

Nakashima K, Ito Y, Yamaguchi-Shinozaki K (2009) Transcriptional regulatory networks in response to abiotic stresses in Arabidopsis and grasses. Plant Physiol 149(1):88-95. https://doi.org/10.1104/pp. 108.129791

Naoumkina MA, Zhao Q, Gallego-Giraldo L et al (2010) Genome-wide analysis of phenylpropanoid defence pathways. Mol Plant Pathol 11(6):829-846. https://doi.org/10.1111/j.1364-3703.2010.00648.x

Novo M, Silvar C, Merino F, Martínez-Cortés T, Lu F, Ralph J, Pomar F (2017) Deciphering the role of the phenylpropanoid metabolism in the tolerance of Capsicum annum L. to Verticillium dahliae Kleb. Plant Sci 258:12-20. https://doi.org/10.1016/j.plantsci.2017.01.014

O'Malley DM, Whetten R, Bao W, Chen CL, Sederoff RR (1993) The role of of laccase in lignification. Plant J 4(5):751-757. https://doi. org/10.1046/j.1365-313X.1993.04050751.x

Peltier AJ, Hatfield RD, Grau CR (2009) Soybean stem lignin concentration relates to resistance to Sclerotinia sclerotiorum. Plant Dis 93(2): 149-154. https://doi.org/10.1094/pdis-93-2-0149

Pichon M, Deswartes C, Gerentes D, Guillaumie S, Lapierre C, Toppan A, Barrière Y, Goffner D (2006) Variation in lignin and cell wall digestibility in caffeic acid O-methyltransferase down-regulated maize half-sib progenies in field experiments. Mol Breed 18(3): 253-261. https://doi.org/10.1007/s11032-006-9033-2 
Rastogi S, Dwivedi UN (2006) Down-regulation of lignin biosynthesis in transgenic Leucaena leucocephala harboring $O$-Methyltransferase gene. Biotechnol Prog 22(3):609-616. https://doi.org/10.1021/ bp050206+

Reiner A, Yekutieli D, Benjamini Y (2003) Identifying differentially expressed genes using false discovery rate controlling procedures. Bioinformatics 19(3):368-375. https://doi.org/10.1093/ bioinformatics/btf877

Robinson MD, McCarthy DJ, Smyth GK (2009) edgeR: a bioconductor package for differential expression analysis of digital gene expression data. Bioinformatics 26(1):139-140. https://doi.org/10.1093/ bioinformatics/btp616

Rogers LA, Dubos C, Surman C, Willment J, Cullis IF, Mansfield SD, Campbell MM (2005) Comparison of lignin deposition in three ectopic lignification mutants. New Phytol 168(1):123-140. https:// doi.org/10.1111/j.1469-8137.2005.01496.x

Sayers EW, Agarwala R, Bolton EE et al (2019) Database resources of the national center for biotechnology information. Nucleic Acids Res 47(D1):D23-D28. https://doi.org/10.1093/nar/gky106

Shi H, Liu Z, Zhu L, Zhang C, Chen Y, Zhou Y, Li F, Li X (2012) Overexpression of cotton (Gossypium hirsutum) dirigent1 gene enhances lignification that blocks the spread of Verticillium dahliae. Acta Biochim Biophys Sin 44(7):555-564. https://doi.org/10.1093/ abbs/gms035

Shi J, Mueller WC, Beckman CH (1991) Ultrastructural responses of vessel contact cells in cotton plants resistant or susceptible to infection by Fusarium oxysporum $f$. sp. vasinfectum. Physiol Mol Plant Pathol 38(3):211-222. https://doi.org/10.1016/S0885-5765(05) 80125-0

Shi J, Mueller WC, Beckman CH (1992) Vessel occlusion and secretory activities of vessel contact cells in resistant or susceptible cotton plants infected with Fusarium oxysporum f.sp. vasinfectum. Physiol Mol Plant Pathol 40(2):133-147. https://doi.org/10.1016/ 0885-5765(92)90040-3

Shi J, Mueller WC, Beckman CH (1993) The inhibition of fungal growth in resistant cotton plants infected by Fusarium oxysporum $f$. $s p$. vasinfectum. J Phytopathol 139(3):253-260. https://doi.org/10. 1111/j.1439-0434.1993.tb01424.x

Smit F, Dubery IA (1997) Cell wall reinforcement in cotton hypocotyls in response to a Verticillium dahliae elicitor. Phytochemistry 44(5): 811-815. https://doi.org/10.1016/S0031-9422(96)00595-X

Tang L, Nie S, Li W, Fan C, Wang S, Wu F, Pan K (2019a) Wheat straw increases the defense response and resistance of watermelon monoculture to Fusarium wilt. BMC Plant Biol 19(1):551. https://doi.org/ 10.1186/s12870-019-2134-y

Tang QY, Zhang CX (2013) Data processing system (DPS) software with experimental design, statistical analysis and data mining developed for use in entomological research. Insect Sci 20(2):254-260. https:// doi.org/10.1111/j.1744-7917.2012.01519.x

Tang Y, Zhang Z, Lei Y, Hu G, Liu J, Hao M, Chen A, Peng Q, Wu J (2019b) Cotton WATs modulate SA biosynthesis and local lignin deposition participating in plant resistance against Verticillium dahliae. Front Plant Sci 10:526. https://doi.org/10.3389/fpls.2019. 00526

Tatusov RL, Galperin MY, Natale DA, Koonin EV (2000) The COG database: a tool for genome-scale analysis of protein functions and evolution. Nucleic Acids Res 28(1):33-36. https://doi.org/10.1093/ nar/28.1.33

Taylor-Teeples M et al (2015) An Arabidopsis gene regulatory network for secondary cell wall synthesis. Nature 5177536:571-575. https:// doi.org/10.1038/nature14099

Trapnell C, Williams BA, Pertea G, Mortazavi A, Kwan G, van Baren MJ, Salzberg SL, Wold BJ, Pachter L (2010) Transcript assembly and quantification by RNA-Seq reveals unannotated transcripts and isoform switching during cell differentiation. Nat Biotechnol 28(5): 511-515. https://doi.org/10.1038/nbt.1621

Tronchet M, Balagué C, Kroj T et al (2010) Cinnamyl alcohol dehydrogenases-C and $\mathrm{D}$, key enzymes in lignin biosynthesis, play an essential role in disease resistance in Arabidopsis. Mol Plant Pathol 11(1):83-92. https://doi.org/10.1111/j.1364-3703.2009. 00578. $\mathrm{x}$

Ullah A, Sun H, Yang X, Zhang X (2017) Drought coping strategies in cotton: increased crop per drop. Plant Biotechnol J 15(3):271-284. https://doi.org/10.1111/pbi.12688

Wang C, He X, Li Y, Wang L, Guo X, Guo X (2018) The cotton MAPK kinase GhMPK20 negatively regulates resistance to Fusarium oxysporum by mediating the MKK4-MPK20-WRKY40 cascade. Mol Plant Pathol 19(7):1624-1638. https://doi.org/10.1111/mpp. 12635

Wang C, He X, Wang X, Zhang S, Guo X (2017) ghr-miR5272a-mediated regulation of GhMKK6 gene transcription contributes to the immune response in cotton. J Exp Bot 68(21-22):5895-5906. https://doi.org/10.1093/jxb/erx373

Wang GF, He Y, Strauch R, Olukolu B, Nielsen D, Li X, Balint-Kurti P (2015) Maize homologs of hydroxycinnamoyltransferase, a key enzyme in lignin biosynthesis, bind the nucleotide binding leucine-rich repeat $R p 1$ proteins to modulate the defense response. Plant Physiol 169(3):2230-2243. https://doi.org/10.1104/pp.15.00703

Xu L, Zhu L, Tu L, Liu L, Yuan D, Jin L, Long L, Zhang X (2011) Lignin metabolism has a central role in the resistance of cotton to the wilt fungus Verticillium dahliae as revealed by RNA-Seq-dependent transcriptional analysis and histochemistry. J Exp Bot 62(15): 5607-5621. https://doi.org/10.1093/jxb/err245

Yang Q, He Y, Kabahuma M, Chaya T, Kelly A, Borrego E, Bian Y, el Kasmi F, Yang L, Teixeira P, Kolkman J, Nelson R, Kolomiets M, L Dangl J, Wisser R, Caplan J, Li X, Lauter N, Balint-Kurti P (2017) A gene encoding maize caffeoyl-CoA O-methyltransferase confers quantitative resistance to multiple pathogens. Nat Genet 49(9): 1364-1372. https://doi.org/10.1038/ng.3919

Yao Z, Chen Q, Chen D et al (2019) The susceptibility of sea-island cotton recombinant inbred lines to Fusarium oxysporum $f$. sp. vasinfectum infection is characterized by altered expression of long noncoding RNAs. Sci Rep 9(1):2894. https://doi.org/10.1038/ s41598-019-39051-2

Zhang J, Mace ME, Stipanovic RD, Bell AA (1993) Production and fungitoxicity of the terpenoid phytoalexins in cotton inoculated with Fusarium oxysporum f. sp. vasinfectum. J Phytopathol 139(3):247252. https://doi.org/10.1111/j.1439-0434.1993.tb01423.x

Zhang L, Wang M, Li N, Wang H, Qiu P, Pei L, Xu Z, Wang T, Gao E, Liu J, Liu S, Hu Q, Miao Y, Lindsey K, Tu L, Zhu L, Zhang X (2018) Long noncoding RNAs involve in resistance to Verticillium dahliae, a fungal disease in cotton. Plant Biotechnol J 16(6):11721185. https://doi.org/10.1111/pbi.12861

Zhang SH, Yang Q, Ma RC (2007) Erwinia carotovora ssp. carotovora infection induced "defense lignin" accumulation and lignin biosynthetic gene expression in Chinese cabbage (Brassica rapa L. ssp. pekinensis). J Integr Plant Biol 49(7):993-1002. https://doi.org/10. 1111/j.1672-9072.2007.00478.x

Zhang Y, Wang X, Rong W, Yang J, Li Z, Wu L, Zhang G, Ma Z (2017) Histochemical analyses reveal that stronger intrinsic defenses in Gossypium barbadense than in G. hirsutum are associated with resistance to Verticillium dahliae. Mol Plant-Microbe Interact 30(12): 984-996. https://doi.org/10.1094/mpmi-03-17-0067-r

Zhang Y, Wu L, Wang X, Chen B, Zhao J, Cui J, Li Z, Yang J, Wu L, Wu J, Zhang G, Ma Z (2019) The cotton laccase gene GhLAC15 enhances Verticillium wilt resistance via an increase in defence- 
induced lignification and lignin components in the cell walls of plants. Mol Plant Pathol 20(3):309-322. https://doi.org/10.1111/ mpp. 12755

Zhong R, Richardson EA, Ye ZH (2007) The MYB46 transcription factor is a direct target of SND1 and regulates secondary wall biosynthesis in Arabidopsis. Plant Cell 19(9):2776-2792. https://doi.org/10. 1105/tpc. 107.053678

Zhu QH, Stephen S, Kazan K, Jin G, Fan L, Taylor J, Dennis ES, Helliwell CA, Wang MB (2012) Characterization of the defense transcriptome responsive to Fusarium oxysporum-infection in
Arabidopsis using RNA-seq. Gene 512(2):259-266. https://doi. org/10.1016/j.gene.2012.10.036

Zhu W, Gao E, Shaban M, Wang Y, Wang H, Nie X, Zhu L (2018) $G h U M C 1$, a blue copper-binding protein, regulates lignin synthesis and cotton immune response. Biochem Biophys Res Commun 504(1):75-81. https://doi.org/10.1016/j.bbrc.2018.08.128

Publisher's Note Springer Nature remains neutral with regard to jurisdictional claims in published maps and institutional affiliations. 